\title{
Static Voltage Security Analysis of Single Branch Outage Contingency
}

\author{
Yousuf Mohammad Younes \\ Department of Electrical Engineering \\ Collage of Engineering, Mosul University \\ Mosul, Iraq
}

\begin{abstract}
This research dealt with the analysis of the static security of the electrical power system according to the security constraints after the transient state of the single outage contingency to recognize the weak points of an electrical power system in future to help the engineers of the operation of the system by taking appropriate decisions to overcome the weaknesses and thus achieve secure systems. The IEEE 14 Bus system was selected as a model for study and representation in MATLAB. This possibility of contingency refers to N-1 Security analysis ( the symbol $\mathrm{N}$ represents all branches of the system: transmission lines or transformers, this is known as the Base Case which is secure ), according to Voltage Performance Index $\left(\mathrm{PI}_{\mathrm{V}}\right)$. By selecting the best ratios for Off Load Tap Transformers and injecting the reactive power to the weakest load bus, the most severe disturbances were overcome.
\end{abstract}

\section{Keywords}

Static voltage security, Single branch outage contingency, Voltage performance index, Off load tap changer.

\author{
Abdul Ghani A. A, Phd \\ Department of Electrical Engineering \\ Collage of Engineering, Mosul University \\ Mosul, Iraq
}

\section{INTRODUCTION}

Security opened new horizons in power system would thus affect the robust of the system operation. It has a major role for reliable operation of the power system networks owing to the fact these networks are subjected to various kinds of unexpected, undetermined continuous changes and unplanned potentially harmful perturbations and highly stressed conditions which may threaten the system. Hence power system security should be covering a wide range of severe operating conditions like a branch (transmission line or transformer) outage, a generator outage or failure , a sudden change in load demand, etc. These severe disturbances are known as the contingencies which may lead to partial (brownout) or complete (blackout) collapse of the system $[1,2]$.To withstand the consequences of severe contingencies, the power system must have the ability to do that, where this ability can be achieved by secure system which gives the power system a minimal probability of blackout and equipment damage, [3,4]. The classification of static security analysis at post contingency is shown in Figure 1,[5]:

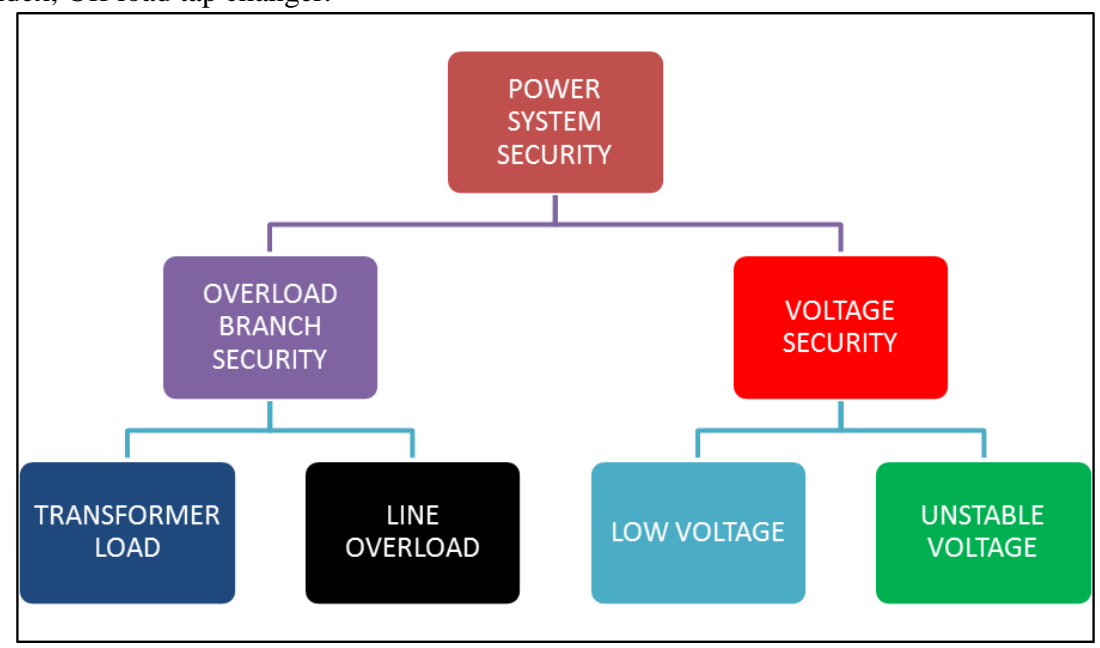

Fig 1: The classification of steady state security at off line security.

From the above figure, static security at steady state is categorized into overload branch security and voltage security. The voltage security can be divided into low voltage security and unstable voltage security. Both overload and low voltage security describe the violation of security limits. Unstable voltage security can be categorized as static or dynamic security because the analysis of unstable voltage has been done in both static and dynamic security [6].

\section{VOLTAGE SECURITY CONSTRAINT}

The security constraints (SC's) or security operational limits which refer to normal (secure) operation of the power system is necessary to recognize the operation state of the power system, if normal or not. The strategy of static security assessment dealt with the evaluation of the power system status for various probable contingencies and the results are compared with system constraints for different post contingency scenarios, the system operating state is labeled as secure, if SC's are satisfied for a given operating condition under contingencies. While if any operation limit of SC's is violated for any post-contingency scenario, the system 
operating state is classified as insecure [7,8]. In order to operate the system within an acceptable security domain, the basic security constraints, two algebraic sets of equations are comprise of equality and inequality constraints run power system operation $[9,10]$.The inequality constraints (I) define a permissible levels limitations within rated values which some system variables must not exceed it. The inequality constraints (I) include bus voltage magnitudes (bus voltage security limits) and thermal limits of transmission lines and transformers (line power flow security limits) [11,12].

In details, the inequality voltage security constraint is:

Bus voltage magnitudes which combine between SSS and SSVS represented by bus voltage security limit:

$$
\left|\mathrm{V}_{\min }\right|_{\mathrm{K}} \leq|\mathrm{V}|_{\mathrm{K}} \leq\left|\mathrm{V}_{\max }\right|_{\mathrm{K}}
$$

Where,

$$
\mathrm{K}: 1,2, \ldots \ldots \mathrm{N}_{\mathrm{b}}
$$

$\mathrm{N}_{\mathrm{b}}$ : the numbers of buses in the system;

$|V|_{\mathrm{k}}$ : the voltage magnitude at bus $\mathrm{k}$;

$\left|V_{\min }\right|_{\mathrm{k}}:$ minimum voltage at bus $\mathrm{k}$

$\left|V_{\max }\right|_{\mathrm{k}}:$ maximum voltage at bus $\mathrm{k}$

\section{VOLTAGE PERFORMANCE INDEX (PIV)}

The contingency ranking is done in the descending order according to value of $\mathrm{PI}_{\mathrm{V}}$ to discriminate the critical contingencies which having $\mathrm{PI}_{\mathrm{V}}$ values greater than " 1 ", to give planners a very quickly list of "worst case" contingencies . Computation of $\mathrm{PI}_{\mathrm{V}}$ it is required to check all voltage buses in the network against their respective limits for each outage tested, generally a margin of the permissible limits is $\pm 5 \%$, i.e., 0.95 p.u. for minimum voltage and 1.05 p.u. for maximum voltage

$[13,14]$.
$\mathrm{W}_{\mathrm{Vi}}$ : the real non-negative weighting factor which is equal to 1 in this equation.

$n$ : the exponent of penalty function ( $n=1$ is preferred)

$\left|\mathrm{V}_{\mathrm{i}}\right|$ : the voltage magnitude at bus $\mathrm{i}$

$\left|\mathrm{V}_{\mathrm{i}}^{\mathrm{sp}}\right|$ the specified (rated) voltage magnitude at bus $\mathrm{i}$ $\Delta \mathrm{V}_{\mathrm{i}}^{\mathrm{Lim}} \mid$ deviations are unacceptable

\section{RESULTS OF SINGLE BRANCH OUTAGE CONTINGENCY}

The CA for N-1 Static Security is tested for any possibility single branch outage using PIV and PIP. The contingencies are then ranked in descending manner where the most severe contingency at the highest value of PIV or PIP.

As it is known the system has 20 branches hence there is 20 single branch outage contingency scenarios.

\section{CONTINGENCY ANALYSIS WHEN ALL TAP CHANGERS RATIOS ARE EQUALE TO 1}

In this case, the procedure is done with tap ratio equal to $1: 1$ for all transformers.

Figure (2a) shows the contingency list (contingency definition) or the graphical representation of the performance index for all the branch contingencies with the value of $\mathrm{PI}_{\mathrm{V}}$ on the $\mathrm{y}$-axis and the outage branch number labeled on the $\mathrm{x}$-axis.

While, figure (2b) shows the contingency ranking of the $\mathrm{PI}_{V}$ in descending manner with the value of $\mathrm{PI}_{\mathrm{V}}$ on the $\mathrm{y}$-axis and the outage line number labeled on the $\mathrm{x}$-axis.

And figure (2c) shows the contingency evaluation of the $\mathrm{PI}_{V}$ for the most severe contingencies with the value of $\mathrm{PI}_{\mathrm{V}}$ on the $y$-axis and the outage line number labeled on the $x$-axis.

From the last figure there are nine branch outages give the most severe contingencies and the maximum $\mathrm{PI}_{\mathrm{V}}$ is done at outage of line 15 and equal to 2.089 while the minimum $\mathrm{PI}_{\mathrm{V}}$ is done at outage of line 9 which equal to 1.001 .

To decrease this number, a tap changer at off load is used to improve the performance of this tested system at N-1 Security.

NB: the number of buses in the system
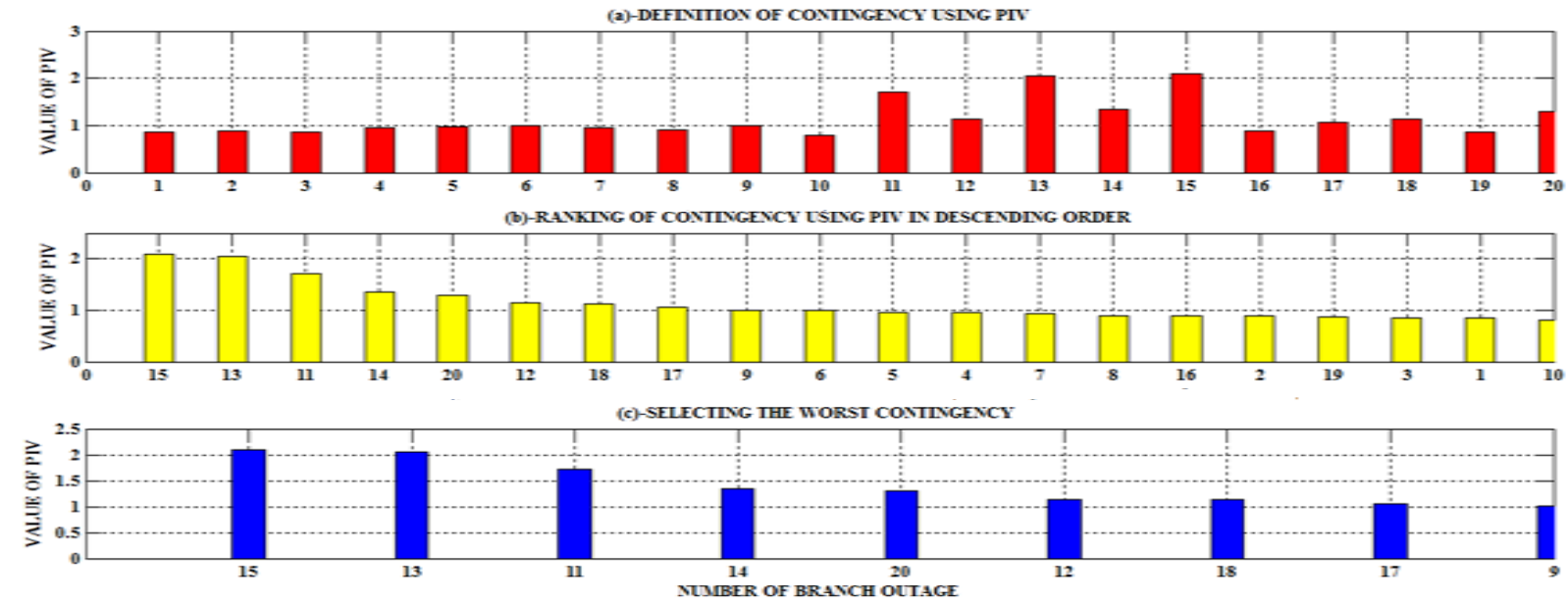

Fig 2: Contingency analysis for N-1 Security of IEEE-14 bus system at all tap ratio=1. 


\section{CONTINGENCY ANALYSIS AT THE SUITABLE VALUES OF TAP CHANGERS RATIOS}

In this case, the procedure is done with $\mathrm{a}_{47}$ equal to $0.932, \mathrm{a}_{49}$ equal to 0.932 and $\mathrm{a}_{56}$ equal to 0.978 according to best values of previous results .

Fig. (3a) shows the contingency list (contingency definition)or the graphical representation of the performance indices for all the branch contingencies.

Fig (3b) shows the contingency ranking of the $\mathrm{PI}_{V}$ in descending manner.

Fig. (3c) shows the contingency evaluation of the $\mathrm{PI}_{V}$ for the most severe contingencies.
From the last figure, the maximum $\mathrm{PI}_{\mathrm{V}}$ is done at outage of line 15 and equal to 1.734 while the minimum $\mathrm{PI}_{\mathrm{V}}$ is done at outage of line 13 and equal to 1.421 .

By comparison figure $3 \mathrm{a}$ and $2 \mathrm{a}$, it is clear that the best state is at $\mathrm{a}_{47}=0.932, \mathrm{a}_{49}=0.932$ and $\mathrm{a}_{56}=0.978$ because it gives the lowest number of critical contingencies which equal to two critical states while at tap ratio for all transformers equal to 1 , as in figure $2 \mathrm{c}$, the lowest number of critical contingencies is equal to nine critical states.

Also, reduction the value of $\mathrm{PI}_{\mathrm{V}}$ for the worst contingency state from 2.089 to 1.734 and rise the value of minimum voltage at worst contingency from 0.9215 to 0.9331 for bus 14 voltage, so the final case is considered the best treatment according to the reasons and results above for all previous cases.
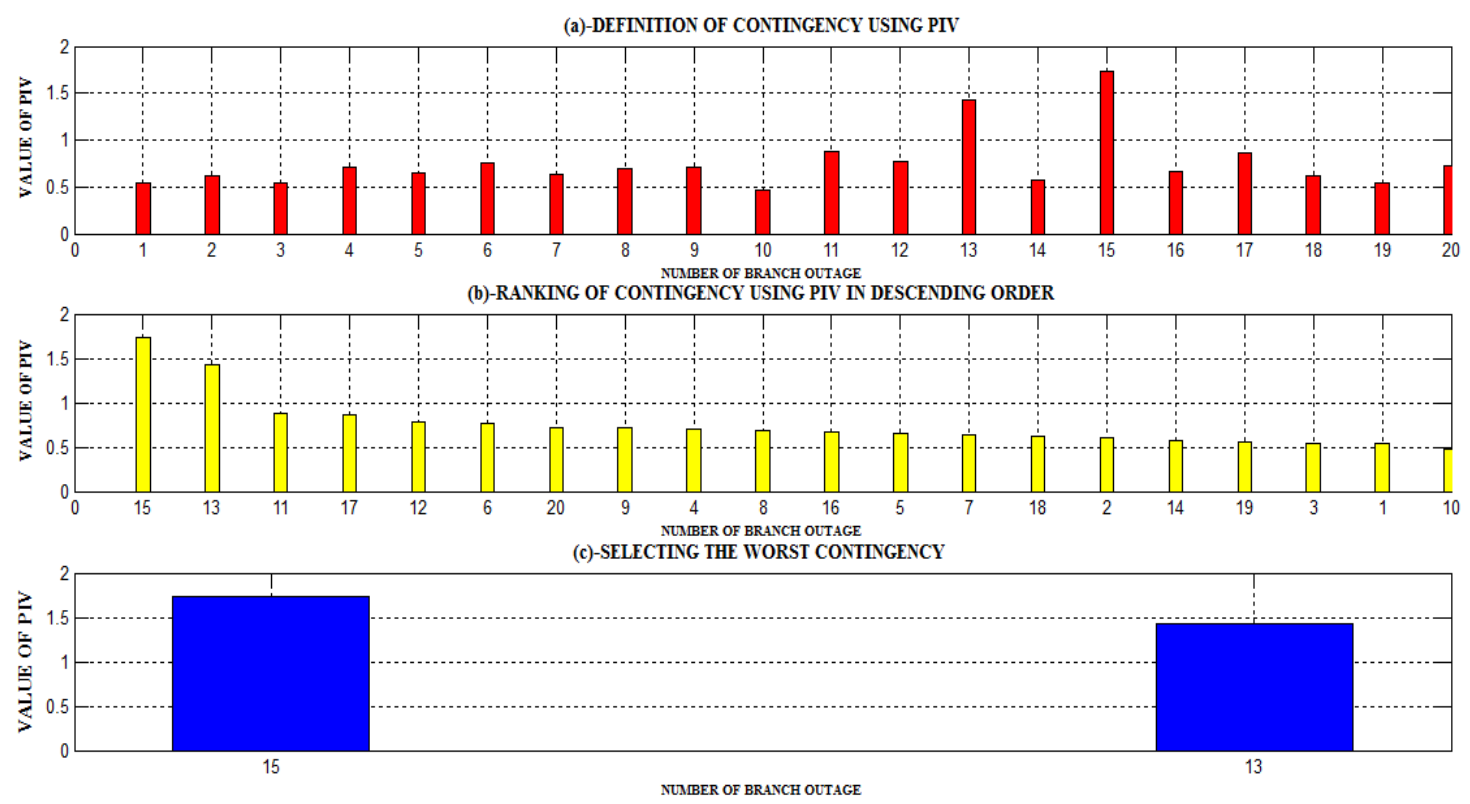

Fig 3: Contingency analysis for N-1 Security of IEEE-14 bus system at best values of tap ratios for all tap transformers

\section{CONCLUSIONS}

The static security analysis of IEEE 14bus was dependent on some performance indices like $\mathrm{PI}_{\mathrm{V}}$ to assess the security.

$\mathrm{PI}_{\mathrm{V}}$ gave a good indication on the security state for different types of contingencies.

The techniques which are used as security control actions were successful because they gave the system the ability to withstand and overcome the harmful contingencies and return the system to secure state.

Contingency analysis is an efficient in probable contingencies definition, selecting the worst cases and evaluating the security state.

The conclusions are summarized, as following:

1- $\quad \mathrm{PI}_{\mathrm{V}}$ is a good indicator for single branch outage contingency.

2- For single outage contingency, Off Load Tap Changer at suitable tap ratio value is efficient equipment because it decreased the worst contingency cases from 15 case to 2 case for the tested system.

\section{REFERENCES}

[1] S. Ravindra, V. C. Veera Reddy and S. Sivanagaraju, "Power System Severity Analysis under Generator Outage Condition", International Journal of Advanced Research in Electrical, Electronics and Instrumentation Engineering, Vol. 4, Issue 1, January 2015.

[2] Brendan Kirby and Eric Hirst, "National Transmission Grid Study", U.S. Department of Energy, May 2002.

[3] Kip Morison, Lei Wang, and Prabha Kundur, "Power System Security Assessment", IEEE power and energy magazine, October 2004.

[4] S. Kalyani, "A Unified Approach for Security Assessment of Power Systems Using Pattern Classifiers", $\mathrm{Ph} . D$. Thesis, Department of Electrical Engineering Indian Institute of Technology Madras, India, October 2010.

[5] S. Kalyani and K. Shanti Swarup, "Study of Neural Network Models for Security Assessment in Power Systems", International Journal of Research and Reviews in Applied Sciences, Volume 1, Issue 2, November, 2009. 
[6] Lamine Mili, "Taxonomy of the Characteristics of Power System Operating States” ,Bradley Department of Electrical and Computer Engineering, Northern Virginia Center, Virginia Tech, January 11th, 2011.

[7] Christian Andersson, "Power System Security Assessment Application of Learning Algorithms", Licentiate Thesis, Department of Industrial Electrical Engineering and Automation, Lund University, Sweden, 2005.

[8] Dilan Supun Jayaweera, "Value of Security Assessment - Extensions and Applications " , Ph.D. Thesis, University of Manchester Institute of Science and Technology, 2003.

[9] P.R. Sharma, Rajesh Kr.Ahuja, Shakti Vashisth and Vaibhav Hudda, "Computation of Sensitive Node for IEEE- 14 Bus system Subjected to Load Variation", International Journal of Innovative Research in Electrical, Electronics, Instrumentation and Control Engineering, Vol. 2, Issue 6, June 2014.
[10] Mohamed E. El-Hawary, "Introduction to Electrical Power Systems", the Institute of Electrical and Electronics Engineers, Inc. 2008.

[11] Prabha Kundur, "Power System Security in the New Industry Environment: Challenges and Solutions", IEEE Toronto Centennial Forum on Reliable Power Grids in Canada, October 3, 2003.

[12] Mohammed Abdulla Abdulsada and Dr. Firas M. Tuaimah, "Power System Static Security Assessment for Iraqi Super High Voltage Grid" , International Journal of Applied Engineering Research, Volume 12, Number 19, 2017.

[13] Amit Kumar Roy, "Contingency Analysis in Power System”, M.Sc.Thesis, Thapar University, Patiala, JULY 2011.

[14] Rohini G D, B Kantharaj and R D Satyanarayana Rao, "Transmission Line Contingency Analysis in Power system using Fast Decoupled Method for IEEE-14 and IEEE-30 bus Test system", International Journal of Engineering Technology and Management (IJETM), Volume 2, Issue 3, May-June 2015. 